\title{
REVIEW
}

\section{What can rodent models tell us about apathy and associated neuropsychiatric symptoms in Parkinson's disease?}

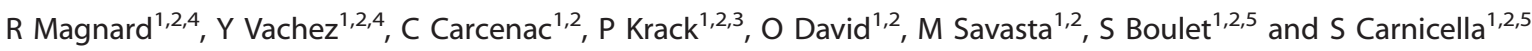

In addition to classical motor symptoms, Parkinson's disease (PD) patients display incapacitating neuropsychiatric manifestations, such as apathy, anhedonia, depression and anxiety. These hitherto generally neglected non-motor symptoms, have gained increasing interest in medical and scientific communities over the last decade because of the extent of their negative impact on PD patients' quality of life. Although recent clinical and functional imaging studies have provided useful information, the pathophysiology of apathy and associated affective impairments remains elusive. Our aim in this review is to summarize and discuss recent advances in the development of rodent models of PD-related neuropsychiatric symptoms using neurotoxin lesionbased approaches. The data collected suggest that bilateral and partial lesions of the nigrostriatal system aimed at inducing reliable neuropsychiatric-like deficits while avoiding severe motor impairments that may interfere with behavioral evaluation, is a more selective and efficient strategy than medial forebrain bundle lesions. Moreover, of all the different classes of pharmacological agents, D2/D3 receptor agonists such as pramipexole appear to be the most efficient treatment for the wide range of behavioral deficits induced by dopaminergic lesions. Lesion-based rodent models, therefore, appear to be relevant tools for studying the pathophysiology of the non-motor symptoms of PD. Data accumulated so far confirm the causative role of dopaminergic depletion, especially in the nigrostriatal system, in the development of behavioral impairments related to apathy, depression and anxiety. They also put forward D2/D3 receptors as potential targets for the treatment of such neuropsychiatric symptoms in PD.

Translational Psychiatry (2016) 6, e753; doi:10.1038/tp.2016.17; published online 8 March 2016

In addition to the cardinal motor symptoms of this progressive neurodegenerative disorder, Parkinson's disease (PD) is also associated with a plethora of non-motor manifestations, such as sleep disturbance, cognitive impairment, psychosis, anxiety, depression, apathy and impulsive/compulsive disorders. ${ }^{1-6}$ This cluster of symptoms, which was largely neglected in the past, and which severely impairs patients' quality of life, is now recognized as a major contributor to morbidity. ${ }^{2,3}$

Apathy and affective disorders such as depression and anxiety appear as major neuropsychiatric features of the disease. ${ }^{1,3,7}$ Apathy, which frequently presents in association with depression and anxiety in PD, is a behavioral syndrome classically defined as a lack of motivation. ${ }^{7-10}$ Its prevalence in PD varies from 17 to $70 \%$ depending on the evaluation scale used and the population studied, ${ }^{5,7}$ and it is now accepted that a large majority of PD patients will develop apathy along the course of disease. ${ }^{1,7,11,12}$ Apathy is also viewed as a major side effect of deep brain stimulation of the subthalamic nucleus (STN-DBS), ${ }^{11,13,14}$ limiting its dramatic motor benefits in terms of patient-related quality of life. ${ }^{15,16}$ Consequently, understanding the pathophysiology of apathy and associated affective syndromes in PD has gained increasing interest in the medical and scientific communities over the last decade.

After a brief introduction on the phenomenology of apathy and the questions raised by some clinical and imaging studies, we will review and discuss recent advances in the development of rodent models of PD-related neuropsychiatric symptoms. Most of these animal lesion studies point toward the critical role of dopamine in the pathophysiological mechanisms underlying apathy and related affective impairments in PD. They may also provide useful information for the pharmacotherapeutic management of such symptoms.

\section{APATHY AS A CORE SYMPTOM OF PD}

Although apathetic symptoms were described very early in $P D,{ }^{17,18}$ awareness of the importance of apathy in the management of PD patients only arose a decade ago. The medical community's lack of interest in this psychiatric impairment was perhaps owing to a lack of nosological clarity. In current psychiatric classification systems, apathy in fact only appears as a feature associated with dementia or with the negative symptoms of schizophrenia, and as a predominant symptom of major depression, overlapping with anhedonia. ${ }^{5,19}$ More recently, apathy was also referenced as one of the features frequently associated with major or mild neurocognitive disorder caused by Parkinson's or Huntington's disease, ${ }^{20}$ in the same way as anxiety and depression, two affective impairments commonly associated with apathy in these neurodegenerative disorders. ${ }^{1,2,9,21,22}$ Apathy could therefore be regarded as a nonspecific symptom, stemming

${ }^{1}$ Inserm U1216, Grenoble, France; ${ }^{2}$ Université Grenoble Alpes, Grenoble Institut des Neurosciences, Grenoble, France and ${ }^{3}$ Movement Disorder Unit, Department of Psychiatry and Neurology, CHU de Grenoble, Grenoble, France. Correspondence: Dr S Carnicella, Inserm U1216, Grenoble Institute of Neuroscience, Site Santé La Tronche - BP 170, 38042 Grenoble, France.

E-mail: sebastien.carnicella@inserm.fr

${ }^{4}$ These two authors contributed equally to this work.

${ }^{5}$ Co-senior authors

Received 2 November 2015; revised 11 January 2016; accepted 19 January 2016 
from a general degradation of cognitive functions, with negligible implications for clinical evaluation or treatment. However, some evidence suggests that apathy is a true clinical construct, ${ }^{8,23}$ with interesting transnosographic features. ${ }^{24-26}$ This led Robert Marin to propose a clear operative definition of apathy and to create the first rating scale in the early 1990s. ${ }^{8,27}$

Apathy can be defined as deficits in goal-directed behaviors (The term 'goal-directed behavior' can be misleading and should be viewed as a 'behavior directed toward a goal' and not as a 'behavior directed by a goal', as the second has a strong theoretical connotation referring to a specific psychobiological process and putative functional sub-compartmentalization of the dorsal striatum. ${ }^{28,29}$ ) or a primary lack of motivation, ${ }^{27}$ characterized by strong deficits in self-initiation and maintenance of voluntary and purposeful behavior, resulting in low levels of activity, loss of socialization and interest in sources of reinforcement. ${ }^{7,30-32}$ The observable phenomenon of apathy can be related to emotional, cognitive and auto-activation subdomains, that are underlined by different dysfunctions of the corticostriatal circuits (the so-called basal ganglia limbic, associative and motor loops) involved in the complex chain of processes that transforms an intention into an adapted action.,30 Therefore, multiple forms of apathy may exist, depending on the respective contribution of each subdomain from one patient to another. Interestingly, a study using an implicit incentive task, revealed that apathy in PD and non-PD patients was associated with an inability to translate an expected reward into effort and action, with no change in the perception of reward value. ${ }^{31}$ The results of this study are in line with recent clinical observations suggesting that the apathetic state described in PD may be particularly linked to the anticipatory subcomponent of anhedonia (which is the absence of any association between pleasure and a specific action), rather than to a change in consummatory responses, which reflect an individual's capacity to experience pleasure when engaged in an enjoyable activity. ${ }^{33,34}$ Overall, this strongly indicates that the core element of at least some forms of apathy in $\mathrm{PD}$, resides in the motivational preparatory processes responsible for initiating and maintaining voluntary actions.

Apathy appears to be closely linked to anhedonia and complaints of fatigue in $\mathrm{PD},{ }^{35,36}$ but it is also frequently associated with depression and anxiety. Clinicians have recently regrouped apathy, depression and anxiety into a category called hypodopaminergic behaviors, in opposition to impulsive/compulsive disorders classified as hyperdopaminergic behaviors, to facilitate the clinical management of behavioral complications in PD. ${ }^{9,37,38}$ In PD, apathetic symptoms, such as fatigue and lack of interest or initiative, together with depression and anxiety, are often reported even before the onset of motor symptoms, or early in the disease, in de novo PD patients. ${ }^{39-42}$ As already mentioned, apathy is also a major complication of STN-DBS, ${ }^{11,13}$ particularly in the first postoperative months, when dopaminergic medication has been greatly reduced. ${ }^{9}$ Apathy can also occur later on, with the progression of dysexecutive syndromes related to diffuse cortical spread of alpha-synucleinopathy. ${ }^{7,43}$ Apathy and associated mood disorders can, moreover, be alleviated at different stages of the disease by dopaminergic treatments, particularly with dopaminergic D2/D3 receptor (D2/D3R) agonists, such as ropinirole, rotigotine, pramipexole or piribedil. ${ }^{9,44-49}$ Apathy in PD therefore appears to depend on patient's dopaminergic state, suggesting that dopamine has an important role in the pathophysiology of these non-motor symptoms. ${ }^{3,5,7,50}$ Functional imaging studies in humans have reported an association between PD-related apathy, anxiety and depression, and the extent of dopaminergic denervation in several brain regions, including the ventral and dorsal striatum and the prefrontal cortex (reviewed in ref. 7). Interestingly, similar dopaminergic dysfunctions have been found in the putamen of apathetic Alzheimer disease and Lewy body dementia patients, ${ }^{51}$ thereby strengthening the case for a relationship between apathy and decreased striatal dopaminergic activity.

Despite this useful information, the exact contribution of a dopaminergic deficit to the development of such behavioral impairments in PD, as well as the real therapeutic potential of the different dopaminergic medications, still need to be determined. For instance, it remains unclear whether apathy and associated mood disorders intrinsically derive from the loss of dopamine in the nigrostriatal system or from the diffusion of the lesion towards more putative limbic areas. ${ }^{7,30}$ Similarly, the aforementioned clinical data clearly suggest that postoperative apathy is the expression of a pronounced hypodopaminergic state revealed by a reduction in dopaminergic medication. ${ }^{9}$ However, STN-DBS may also contribute to the occurrence or aggravation of this syndrome by interfering with the neuronal activity of the non-motor territories of the STN or by stimulating fiber tracts in close vicinity to the STN. ${ }^{52-54}$ In addition, it has been shown that STN-DBS can interfere directly with dopaminergic function in rats. ${ }^{55}$ Animal models are clearly useful tools to demonstrate dopamine's causal contribution to the pathophysiology of apathy and associated affective disorders in PD. They can also serve to disentangle the respective implication of each potential factor.

\section{PD-RELATED BEHAVIORAL IMPAIRMENTS IN RODENT MODELS}

Because apathy is operationally defined as a motivational deficit and is frequently associated with depression and anxiety, PubMed and Scopus databases were searched for literature concerning non-motor behaviors in PD-related rodent models (that is, mice and rats) restricted to the evaluation of motivated, anhedonic-like, depression-like or anxiety-like behaviors. References of the publications selected were hand-searched carefully and crossreferenced to find any additional potentially relevant studies. The main information provided by these publications was summarized according to the type of lesional strategy used (Table 1) and to the type of pharmacological treatment used to reverse the behavioral phenotypes induced by the dopaminergic lesions (Table 2). A column was added in Table 1 to indicate the presence or absence of motor impairment, as this may bias interpretation of behavioral results. ${ }^{56,57}$

\section{MOTIVATIONAL DEFICITS}

Effects of bilateral and partial dopaminergic lesions of the nigrostriatal pathway

Evaluating operant behaviors in rodents appears particularly relevant for the study of the psychobiological mechanisms underlying apathy, because it allows a fine and sophisticated evaluation of motivational preparatory processes in both human and non-human species (for review, see ref. 78). Partial dopaminergic denervation, limited to the nigrostriatal system ( $<80 \%$ tyrosine hydroxylase immunoreactivity loss within the dorsal striatum and $<20 \%$ tyrosine hydroxylase immunoreactivity loss within the nucleus accumbens) and induced by the bilateral stereotaxic infusion of the catecholaminergic neurotoxin 6-hydroxydopamine (6-OHDA) into the substantia nigra pars compacta $(\mathrm{SNc})$, dramatically impaired operant behaviors in rats (Table 1). ${ }^{56,61,62}$ Specifically, diminished performance in a runway task involving getting to and eating palatable food, and a significant reduction in instrumental response to sucrose in an operant self-administrating procedure were observed in 6-OHDASNc-lesioned rats. ${ }^{56}$ Importantly, because the partial SNc lesion altered neither sensorimotor coordination on a rotarod nor finemotor velocity in an automated laboratory gait analysis system, these deficits cannot be attributed to motor impairments. ${ }^{56}$ Moreover, the ability of lesioned animals to press an operant lever at short intervals was preserved. ${ }^{61}$ Similarly, these results cannot 


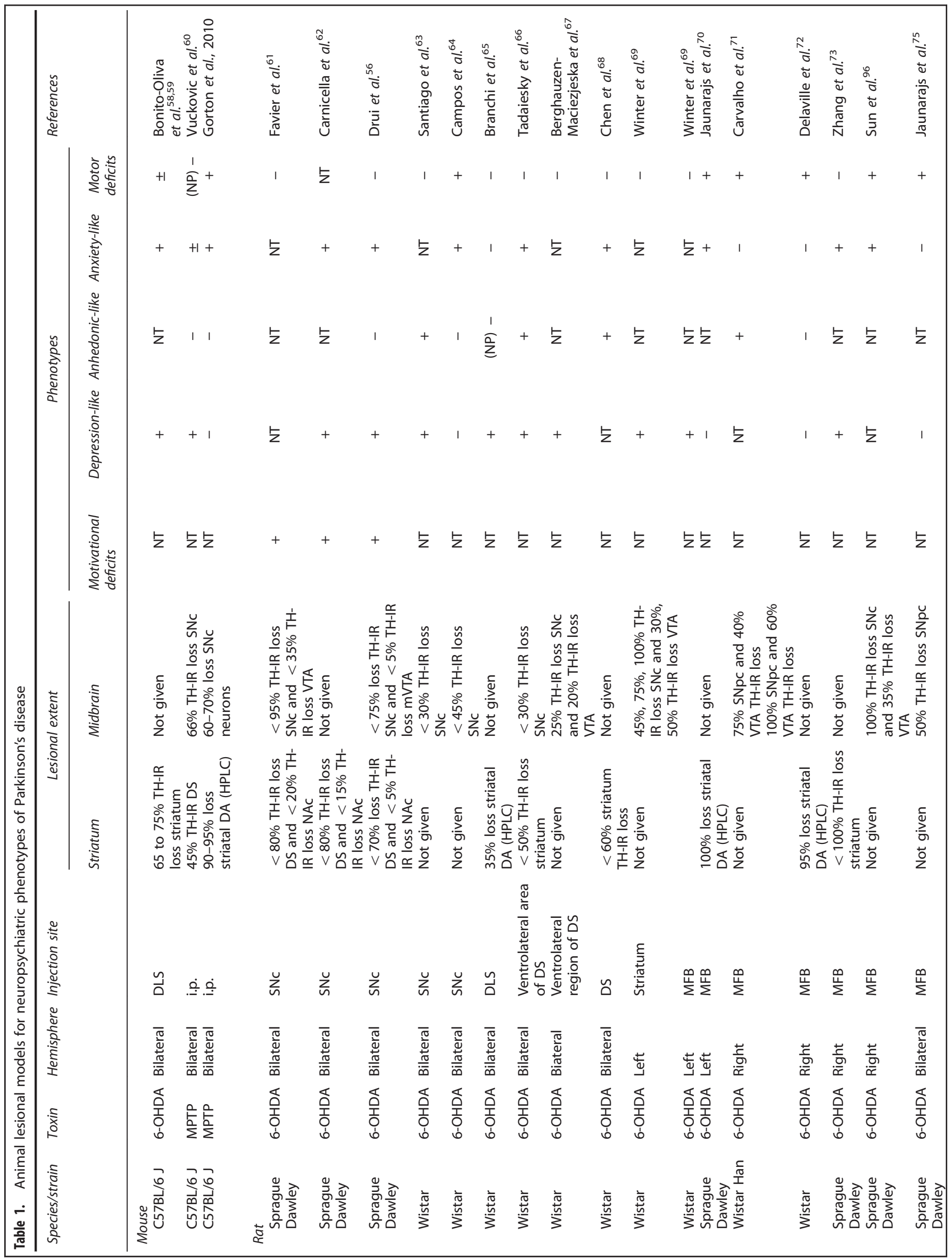




\section{4}

be attributed to an alteration of the rewarding/reinforcing properties of the reinforcers because neither conditioned place preference for the palatable food used in the runway, nor preference for sucrose in a two-bottle choice procedure, were impaired by the dopaminergic lesion. ${ }^{56}$ Therefore, a marked motivational deficit was observed specifically when an instrumental preparatory action was required, a behavioral phenotype that appears highly reminiscent of at least some forms of apathy. ${ }^{7,30,31}$

These data also corroborate the observation that severe, unilateral dopaminergic depletion, targeting, but not restricted to, the dorsal striatum or bilateral dopaminergic depletion restricted to the dorsal striatum, reduced operant performances of rats in a choice reaction time task. ${ }^{79,80}$ Rats with bilateral partial SNc lesions induced by 6-OHDA also exhibited increased latency to complete the 100-pellet test. ${ }^{81}$ Although consummatory or finemotor deficits may contribute to these results, ${ }^{81}$ overall, the aforementioned data ${ }^{56,79}$ suggest that increased latency in reaching and eating a large number of food reward pellets, which requires, as in the runway task, a high degree of behavioral activation, ${ }^{82}$ reflects a real decrease in motivation.

Effects of bilateral and partial dopaminergic lesions of the mesolimbic pathway

Some studies suggest that apathy and associated neuropsychiatric symptoms in PD may stem from dysfunctions of the dopaminergic mesocorticolimbic system. ${ }^{9,10}$ Partial and bilateral 6-OHDA lesions affecting the medial ventral tegmental area (medial VTA) were therefore also performed (Table 1 and ref. 56) in order to mimic the partial dopaminergic denervation of the ventral striatum that frequently occurs in PD patients, especially in the late stage of the disease. ${ }^{83,84}$ Interestingly, none of the motivational deficits described in the section 'Effects of bilateral and partial dopaminergic lesions of the nigrostriatal pathway' above were observed with a $60-70 \%$ loss of dopaminergic innervation in the nucleus accumbens ${ }^{56}$ (see also ref. 81). As the mesolimbic dopaminergic system is a key player in reward-related and goal-directed behaviors, ${ }^{85,86}$ this absence of effect may appear counterintuitive. However, as we have known even since the early days of 6-OHDA use, ${ }^{87}$ a complete, or near complete, loss of dopamine in the mesolimbic pathway is necessary to obtain a reduction in motivated behavior (for review, see refs 88,89 ). Thus, this striking dissociation between the behavioral effects of a partial dopaminergic lesion of the VTA or the SNc clearly strengthens the case for the involvement of the nigrostriatal system in the pathophysiology of apathy in PD on top of the mesolimbic and mesocortical projection systems.

Pharmacological treatments

To further investigate the role of dopamine, different dopaminergic agents classically used in PD were tested on the motivational deficits induced by a partial and bilateral nigrostriatal lesion (Table 2). The D2/D3R agonists ropinirole and pramipexole, efficiently corrected the decrease in operant sucrose selfadministration induced by the SNc lesions, whereas the dopamine precursor L-DOPA did not. ${ }^{56,61}$ Moreover, this deficit was not reversed by subchronic administration of the selective serotonin reuptake inhibitor (SSRI) citalopram. Using more selective dopaminergic receptor subtype agonists, the motivational deficits induced by the SNc lesions were specifically reversed by the D3R agonist PD-128907, but not by the D1R agonists SKF-38393 and SKF-82958, nor by the D2R agonist sumanirole. ${ }^{62}$ Taken together, these data confirm the implication of dopamine and point toward the targeting of D3R for reversing the motivational deficits related to PD. 


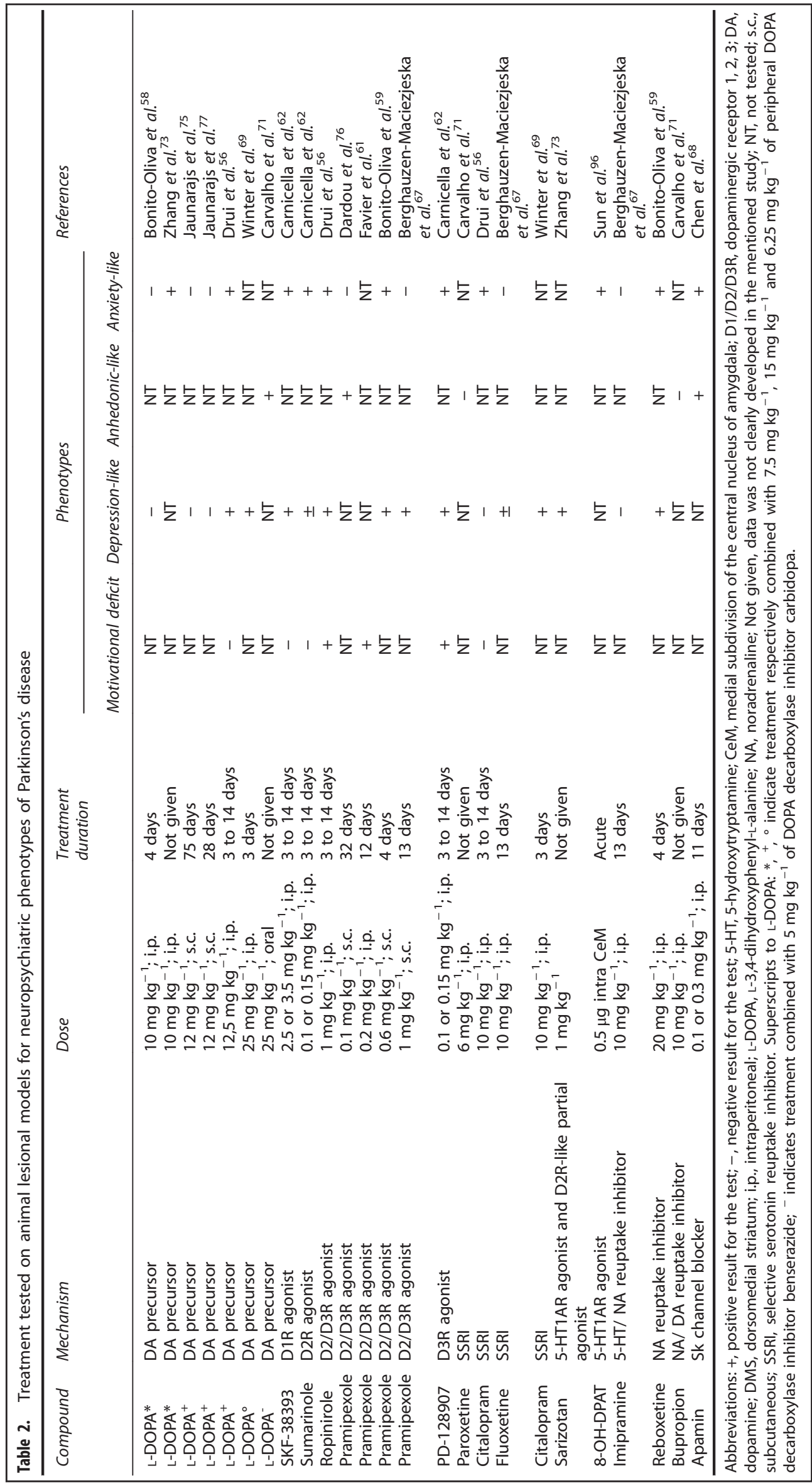




\section{DEPRESSION-LIKE BEHAVIORS}

Effects of bilateral and partial dopaminergic lesions of the nigrostriatal pathway

In keeping with the high incidence of depressive symptoms in PD patients, most of the studies found that partial and bilateral dopaminergic denervation of the nigrostriatal pathway induces a depression-like phenotype (Table 1). Indeed, anterograde and retrograde dopaminergic lesions of the dorsal striatum increased immobility, a classical behavioral index of depression-like state, ${ }^{90}$ in the forced-swim test (FST) as well as in the tail-suspension test, in rats and mice, respectively. Importantly, motor impairments cannot account for a reduction in swimming or climbing, as no major motor deficits were identified with these partial-lesion approaches. ${ }^{56,65,66,68}$

Effects of bilateral and partial dopaminergic lesions of the mesolimbic pathway

Although the mesolimbic dopaminergic system has been shown to be involved in the regulation of mood and depression-related behaviors, ${ }^{91,92}$ partial dopaminergic lesion of the VTA did not increase the time that rats spent immobile in a FST. ${ }^{56}$ However, there is a lack of data and more studies are needed to determine the potential impact of partial dopaminergic denervation of the mesolimbic pathway on such behaviors.

Effects of MPTP and 6-OHDA medial forebrain bundle lesions Studies on mice using systemic administration of MPTP (1-methyl4-phenyl-1,2,3,6-tetrahydropyridine) toxin, and on rats using unilateral or bilateral 6-OHDA medial forebrain bundle (MFB) lesion usually result in extensive and non-selective dopaminergic lesions affecting both the nigrostriatal and mesolimbic pathways. $^{69,71}$ As shown in Table 1, such lesion-based strategies have yielded conflicting results: some studies showed increased immobility in the tail-suspension test ${ }^{60}$ or increased latency in terminating foot shock presentation during a learned helplessness test, $^{69}$ whereas others did not observe any depression-like behaviors in rodents, ${ }^{72,77}$ even in the case of bilateral 6-OHDAMFB lesions. ${ }^{75}$ The absence of lesional selectivity and the presence of motor impairments in these studies are likely to account for these conflicting results, thereby revealing a strong limitation of MFB and MPTP lesions in the study of non-motor behaviors in rodents.

\section{Pharmacological treatments}

Regarding motivational deficits, dopaminergic agents were tested to reverse depression-like phenotypes in rodent models of PD (Table 2). Subchronic administration of L-DOPA has been shown to correct the increase in immobility of lesioned rats in the $\mathrm{FST}^{56}$ and to reduce latency in terminating the foot shock in a learned helplessness procedure. ${ }^{69}$ However, other studies failed to show any beneficial effect of L-DOPA on depression-like behaviors in rats $^{70,75}$ or mice. ${ }^{58}$ By contrast, D2/D3R agonists such as pramipexole, consistently improved depression-like behaviors, whatever the lesional or animal model used. Similar positive results were obtained with selective D1R, D2R or D3R agonists. ${ }^{62}$

Surprisingly, inconsistent effects were found with SSRIs (Table 2) and these mixed results may be a product of the behavioral tests and/or the lesional model used. For instance, citalopram reduced depression-like behaviors in unilateral MFB-lesioned rats in a learned helplessness procedure, ${ }^{69}$ but not in bilateral SNc-lesioned rats in the FST. ${ }^{56}$ Fluoxetine significantly decreased FST-immobility in controls but not in rats with retrograde dopaminergic lesions of the dorsal striatum. ${ }^{67}$ Finally, the serotonin/noradrelanine reuptake inhibitor imipramine failed to improve depression-like behaviors in the same study, ${ }^{67}$ whereas the noradrenaline reuptake inhibitor reboxetine succeeded in 6-OHDA-lesioned mice, ${ }^{58}$ as did sarizotan, a serotoninergic and dopaminergic partial receptor agonist, in unilateral MFB-lesioned rats. ${ }^{73}$ It should also be highlighted that these studies also differ in terms of treatment duration, which is a critical factor to obtain efficient antidepressant actions using SSRI. Indeed, the same dose of fluoxetine has been found to significantly reduce depression-like behaviors after 21 (ref. 93) but not 13 (ref. 67) days of subchronic administration. More consideration should be given to this methodological issue in the future.

Overall, these data strongly indicate the predominant involvement of dopamine, and of the other monoaminergic systems, in parkinsonian-related depression-like behaviors, and show that the dopaminergic receptors are potential therapeutic targets for the treatment of depression in PD.

\section{ANHEDONIA-LIKE BEHAVIORS}

\section{Lesional effects}

Hedonic processes can be divided into consummatory and anticipatory subcomponents, at least from a psychological and neurobiological point of view. ${ }^{3,34}$ In this part of the review, we will use the term anhedonia to refer only to deficits in rewardrelated processes accompanied by a failure to experience pleasure leading to a reduction in consummatory behavior (that is, the equivalent of 'liking' deficits, as termed by Berridge ${ }^{85}$ ). However, because subjective feelings such as pleasure remain quite difficult to apprehend in rodents, from an operational point of view, we refer to anhedonia in preclinical studies as a behavioral insensitivity to the rewarding or reinforcing properties of a specific substance or event.

All the studies summarized in Table 1 used two-bottle choice procedures with water and sucrose as the rewarding solution to assess anhedonia. No clear results emerged from this literature, irrespective of the type of lesional strategy used, which may be due to behavioral protocol differences in these studies and due to the difficulty in isolating and accurately assessing this psychobiological subcomponent of motivated behaviors. Some studies used food and water deprivation before testing, ${ }^{60,64,65,71}$ or short $1 \mathrm{~h}$ (ref. 68) versus standard $24 \mathrm{~h}$ access to the sucrose solution, and this may have interfered with the task by influencing motivational processes. Moreover, all the studies did not use the same sucrose concentration. For instance, partial and bilateral dopaminergic lesions of the nigrostriatal pathway have been found to reduce preference for a 0.5 or a $0.8 \%$, but not for a $2 \%$ sucrose solution. ${ }^{56,66,68}$ When preference was reduced, it was also unclear whether this resulted from a decrease in sensitivity to the rewarding properties of sucrose or from a metabolic confounding factor because lesions of this type can interfere dramatically with hypothalamic function. ${ }^{94}$ In order to exclude this potential bias, one study replaced sucrose with saccharin and found that preference for this non-caloric sweetener was preserved in SNclesioned rats. ${ }^{56}$

A growing body of evidence suggests that dopamine is more involved in motivational ('wanting' or anticipatory/preparatory) behaviors than in rewarding or hedonic processes per se ('liking' or consummatory behaviors). ${ }^{85,95}$ These studies do not, therefore, make it clear whether or not dopaminergic lesions really can induce anhedonia or emotional apathy in humans.

\section{Pharmacological treatments}

Very few drugs have been tested on these types of behavior (Table 2). However, results suggest a specific involvement of dopamine, as L-DOPA ${ }^{71}$ and apamin, a SK channel blocker originally isolated from bee venom known to stimulate the dopaminergic function, improved anhedonia-like behaviors, ${ }^{68}$ while the SSRI paroxetine and the noradrenaline/dopamine reuptake inhibitor bupropion failed to do so. ${ }^{71}$ 


\section{ANXIETY-LIKE BEHAVIORS}

Lesional effects

As is the case for depression-like behaviors, partial and bilateral dopaminergic denervation of the nigrostriatal pathway consistently induced anxiety-related behaviors (Table 1, but see ref. 65). Anterograde and retrograde dopaminergic lesions of the dorsal striatum reduced the amount of time spent in the open arms of an elevated plus maze, a classical index of anxiety. Reduced latency to enter into the dark side of a light/dark avoidance apparatus was also observed in SNc-lesioned rats. ${ }^{56}$ Moreover, 6-OHDA SNclesioned mice exhibited a pronounced increase in thigmotaxis, as indicated by a reduction in time spent in the center of the openfield apparatus. ${ }^{58}$ Again, no consistent results were obtained from studies using 6-OHDA MFB lesions (Table 1).

Interestingly, bilateral and partial lesion of the VTA did not induce an anxiety-like phenotype, either in the elevated plus maze ${ }^{56,76}$ or in the light/dark avoidance test, ${ }^{56}$ thereby strengthening the implication of the dopaminergic nigrostriatal system in the regulation of affective and emotional functions.

\section{Pharmacological treatments}

In keeping with the deleterious impact of nigrostriatal dopaminergic denervation on mood, anxiety-related behaviors in lesioned animals have been shown to be responsive to dopaminergic medication, especially to dopaminergic receptors agonists (Table 2). For instance, anxiety-like behaviors in lesioned mice in the elevated plus maze were reversed by pramipexole but not by L-DOPA, ${ }^{58}$ suggesting a greater efficacy of direct receptor agonists. Interestingly enough, while some agonists such as ropinirole, pramipexole or the D3R agonist PD-128907 normalized anxietyrelated behaviors to the level of control animals, ${ }^{56,58,62}$ the D1R agonist SKF-38393 and the D2R agonist sumanirole produced striking anxiolytic effects on lesioned rats. ${ }^{62}$ Depending on the dose used, SKF-38393 and sumanirole could increase the time spent in the open arms of the elevated plus maze, in SNc-lesioned rats specifically, to levels far above those obtained in their respective control conditions, and promoted disinhibition and risk-taking behaviors, as reflected by an increased number of head dippings and reduction of risk assessments. ${ }^{62}$ Although these data deserve further investigation, they already provide useful information about the iatrogenic mechanisms of dopaminergic medications that may lead to the development of impulsive/compulsive disorders in PD.

In addition to the dopaminergic system, preclinical studies suggest that targeting the other monoaminergic systems may also be a valuable strategy for the treatment of anxiety in PD. For instance, systemic administration of serotoninergic or noradrenergic reuptake inhibitors efficiently improved anxiety-related behaviors in lesioned animals ${ }^{56,58}$ (but see refs 67). Similar beneficial effects were obtained with intra-amygdala or -prelimbic infusion of the 5 -HT1A receptors agonist $8-\mathrm{OH}$-DPAT. ${ }^{74,96}$

\section{CONCLUSIONS AND FUTURE DIRECTIONS}

Models based on 6-OHDA-lesioned rats constitute the most widely used and best-characterized experimental approach for PD.97 Initially developed to study motor symptoms (for review, see ref. 97), all 6-OHDA models are not equivalent and relevant when it comes to mimic and examine the neuropsychiatric symptoms observed in PD, that is, apathy, depression, anhedonia and anxiety. The recent studies reviewed here tend to show that a selective, partial and bilateral lesion of the nigrostriatal dopaminergic pathway (with a retrograde or an anterograde strategy) is probably the most suitable approach in the investigation of the neurobehavioral mechanisms that underlie neuropsychiatric symptoms in PD using 6-OHDA. There is now a large body of evidence highlighting the critical role of the dopaminergic nigrostriatal system-the major neuronal group known to degenerate in PD-in motivational, affective and cognitive impairments. Although this role was previously largely neglected and mainly attributed to the dopaminergic mesoaccumbal pathway, ${ }^{98}$ these data are consistent with pioneering studies supporting a role of nigrostriatal dopamine in motivation ${ }^{99-102}$ or with more recent evidence based on electrophysiological recordings in monkeys ${ }^{103,104}$ (for review, see ref. 86) and selective optogenetic modulation of nigral dopaminergic neurons. ${ }^{105,106}$ Furthermore, partial and selective lesion of this nigrostriatal pathway allows the circumvention of motor symptoms, a major bias in the study of non-motor symptoms. ${ }^{57}$ Such an advantage is not found in more widespread lesional models such as MFB lesion. . $^{606,69,71,72}$

In addition, the relevance of rodent models based on partial and selective degeneration of the nigrostriatal pathway is strengthened by their important predictive value concerning the pharmacological treatment used to reverse neuropsychiatric symptoms in clinic. Interestingly, the pharmacological studies summarized in this review show that medications which produce positive results on motivational deficits are also effective on depression- and anxiety-like behaviors, and on anhedonia-like behaviors, potentially indicating some common mechanisms between these neuropsychiatric symptoms in PD. ${ }^{56,59,61,62,68,69,71}$ Even if these mechanisms remain elusive, these data, overall, highlight the major implication of dopamine and clearly indicate that dopaminergic receptors constitute promising therapeutic targets. On this last point, the literature presented here suggests that direct agonists such as pramipexole or ropinirole may be more efficient to reduce neuropsychiatric symptoms of PD than a more global modulation of dopaminergic neurotransmission with L-DOPA. More precisely, it indicates that pharmacological interventions on D3R are especially appropriate for the reversal of these deficits, as can be seen from the fact that the D3R-prefering PD-128907 reversed motivational deficits in PD models, whereas the D2R selective agonist sumanirole did not (Table 2). Importantly, the D3R is suspected to be a key player in the control of affective and motivated behaviors and as such, has been identified as a potential target for the treatment of neuropsychiatric symptoms in several disorders. ${ }^{107,108}$ D3R expression is particularly high within the ventral striatum, but is also detectable in the dorsal striatum, ${ }^{109-111}$ where it has been shown to significantly participate in the control of motivated behaviors. ${ }^{111,112}$ In accordance with the existing overlap between VTA and SNc dopaminergic projections ${ }^{113}$ and the emerging role of the dorsal striatum in non-motor behaviors (for review, see also refs 86 ), this distribution challenges the oversimplified vision of perfectly segregated systems which serve specific functions (that is, limbic, associative and motor). This appears even more relevant in $\mathrm{PD}$, where dopaminergic denervation in combination with dopaminergic treatments can lead to complex and widespread postsynaptic redistribution of D3R, with notably a strong increase of its expression in the dorsal striatum. ${ }^{109,114}$ Because of this interesting predictive and potential face and construct validity, these rodent models could also serve to determine the relative psychotropic potencies of the different dopaminergic medications. ${ }^{115}$ It corresponds to a clinical need, ${ }^{116}$ namely to avoid a potential source of hypo- and hyperdopaminergic psychiatric side effects in the management of PD, as L-dopa equivalent dosages of different dopamine agonists are only known for motor effects.

Some studies in non-human primates also confirm a major involvement of dopamine in the pathophysiology of apathy in PD. For instance, MPTP lesions in monkey can lead to a decrease in behavioral activity ${ }^{117}$ and goal-directed behaviors, ${ }^{118,119}$ and to social behavioral changes. ${ }^{120}$ However, because of the lack of neuroanatomical selectivity of systemic MPTP administration, and despite in-depth multi-correlational and neuroimaging analyses, it 
has yet to be determined from these studies whether these behavioral impairments result from a loss of dorso- or ventrostriatal function.

Although the dopaminergic system seems to have a crucial role in the physiopathology of neuropsychiatric symptoms in PD, it does not exclude the implication of the other monoaminergic systems, particularly when the strength of their interconnections is taken into consideration. The noradrenergic and serotoninergic systems are also affected in $\mathrm{PD}^{72}$ and some of the neurochemical, ${ }^{66}$ behavioral and pharmacological studies $56,58,69,72,121$ reviewed here support their potential implication in non-motor impairments. Affective-related impairments in lesioned animals can indeed be reduced by SSRIs or noradrenergic reuptake inhibitors (Table 2). Moreover, affective-related behaviors in rats with unilateral dopaminergic lesions may emerge only in combination with serotoninergic and/or noradrenergic depletion $^{72}$ and the degree of depression-like behaviors in 6OHDA-lesioned rats has been recently shown to correlate with hippocampal and striatal serotoninergic dysfunctions. ${ }^{63,122}$ Functional imaging studies in humans and other clinical evidence also suggest that depression and fatigue in PD are associated with alterations of the serotonergic system (reviewed in ref. 123), and, in addition to dopamine, anxiety, depression and apathy in PD patients may also be associated with a greater loss of noradrenaline in the locus coeruleus and noradrenergic innervation in the ventral striatum and other limbic areas. ${ }^{10}$ Although more studies are needed to decipher the specific role of these different neurotransmitter systems, it might indicate that PD ought to be considered as a monoaminergic pathology. Combining pharmacotherapies, to target the three monoaminergic systems, may therefore be a particularly valuable strategy in the treatment of neuropsychiatric symptoms related to the neurodegenerative process in PD.

Taken together, the preclinical results reviewed here clearly favor the hypothesis that postoperative apathy rather results from the reduction of the dopaminergic medication following DBS thereby revealing a strong hypodopaminergic state related to non-motor functions - than by STN-DBS per se. How dopaminergic denervation of a putative motor system interferes so strongly with motivated and affective-related behaviors remains, however, unclear. As already aforementioned, the three so-called limbic, associative and motor cortico-striato-cortical loops are not fully segregated, with an ascending striato-midbrain-striatal spiraling circuitry, ${ }^{28,124-126}$ that functionally interconnects the different corticostriatal regions and associated structures, ${ }^{127,128}$ and a high degree of overlap and convergence between these functional territories within the STN. ${ }^{14,129}$ One can therefore speculate that loss of nigrostriatal dopamine might influence non-motor functions through these subcortical interactions, thereby disrupting the complex chain of events that bridges emotions to actions. A similar scenario can be envisaged within the framework of the actor-critic model of the basal ganglia, ${ }^{130,131}$ with a functional disconnection of the actor (the dorsal striatum) and the critic (the ventral striatum). Depending on the studies, it is suggested that STN-DBS can induce either hypomania and euphoria ${ }^{132-135}$ or apathy. ${ }^{52,53}$ The STN is a small nucleus quite difficult to target and differences in electrode localizations may partly account for these discrepancies. Specifically, induction of hypomania may be associated with stimulation of ventral, that is, limbic, parts of the STN, ${ }^{134,135}$ whereas inaccurate electrode placements or exaggerated current wide-spreading to surrounding areas, such as the substantia nigra pars reticulata, ${ }^{136}$ or pallidothalamic fiber tracts ${ }^{54}$ may exert opposite actions. It may, therefore, be of great interest to investigate how the dopaminergic lesion and DBS may interact agonistically or antagonistically, by dissecting the effects of STNDBS on the three cortico-striato-cortical loops using, for example, optogenetics tools. ${ }^{137}$
In conclusion, toxin-induced lesions of the nigrostriatal DAergic neurons that have been used to model PD in rodents since the 1960 s have recently been re-evaluated for their ability to model some non-motor symptoms and neuropsychiatric symptoms in particular. Thus, efforts have begun to shift away from models that induce destruction of the vast majority of the DA cells of the SNC to more gradual and specific models that allow for the analysis of non-motor symptoms. Nevertheless, in the future, the study of non-motor symptoms in PD will need to be extended to recently developed genetic- or AAV a-synuclein-based rodent models, as interesting complementary approaches to study the occurrence of neuropsychiatric symptoms throughout the progressive neurodegenerative process characteristic of PD. Viral vector-induced overexpression of wild-type human a-synuclein in nigral dopaminergic neurons of rats, for instance, induced a depression-like phenotype. ${ }^{138}$ Transgenic mice expressing human a-synuclein also showed early and severe olfactory deficits, ${ }^{139}$ reproducing one of the most prominent non-motor, and premotor, symptoms of PD. ${ }^{2,3}$ These studies highlight how relevant genetic and viral approaches are in the quest to unravel the mechanisms underlying neuropsychiatric symptoms in PD, to screen drugs and to test the efficiency, or to reveal potential side effects, of neurosurgical approaches such as DBS on such non-motor symptoms. $^{64,140,141}$

\section{CONFLICT OF INTEREST}

PK was granted funds from Medtronic, St Jude and Boston Scientific for research purposes in the field of deep brain stimulation and received research support from Orkyn, Novartis, UCB, LVL and Boston Scientific. He received reimbursement of travel expenses to scientific meetings or honoraria for lecturing or consultation from Medtronic, Euthérapie Company, Novartis Pharma, UCB, St Jude, Lundbeck, Boehringer Ingelheim, Orkyn, Abbott, Orion, TEVA and Boston Scientific. The remaining authors declare no conflict of interest.

\section{ACKNOWLEDGMENTS}

This work was supported by the Institut National de la Santé et de la Recherche Médicale, Fondation NeuroDis, Association France Parkinson, Ministère de la Recherche et de la Technologie (MRT), Région Rhône-Alpes (ARC 2), Fondation de France, Agence nationale de la recherche (ANR13 SAMA001401) and Grenoble Alpes University. We thank Catherine Dalmolin for English language corrections.

\section{REFERENCES}

1 Aarsland D, Marsh L, Schrag A. Neuropsychiatric symptoms in Parkinson's disease. Mov Disord 2009; 24: 2175-2186.

2 Chaudhuri KR, Healy DG, Schapira AH. Non-motor symptoms of Parkinson's disease: diagnosis and management. Lancet Neurol 2006; 5: 235-245.

3 Chaudhuri KR, Schapira AH. Non-motor symptoms of Parkinson's disease: dopaminergic pathophysiology and treatment. Lancet Neurol 2009; 8: 464-474.

4 Voon V, Mehta AR, Hallett M. Impulse control disorders in Parkinson's disease: recent advances. Curr Opin Neurol 2011; 24: 324-330.

5 Sierra M, Carnicella S, Strafella AP, Bichon A, Lhommee E, Castrioto A et al. Apathy and impulsive control disorders: Yin \& Yang of dopamine dependent behaviors. J Parkinsons Dis 2015; 5: 625-636.

6 Bastide MF, Meissner WG, Picconi B, Fasano S, Fernagut PO, Feyder M et al. Pathophysiology of L-dopa-induced motor and non-motor complications in Parkinson's disease. Prog Neurobiol 2015; 132: 96-168.

7 Pagonabarraga J, Kulisevsky J, Strafella AP, Krack P. Apathy in Parkinson's disease: clinical features, neural substrates, diagnosis, and treatment. Lancet Neurol 2015; 14: 518-531.

8 Marin RS. Differential diagnosis and classification of apathy. Am J Psychiatry 1990; 147: 22-30.

9 Thobois S, Ardouin C, Lhommee E, Klinger H, Lagrange C, Xie J et al. Non-motor dopamine withdrawal syndrome after surgery for Parkinson's disease: predictors and underlying mesolimbic denervation. Brain 2010; 133: 1111-1127.

10 Remy P, Doder M, Lees A, Turjanski N, Brooks D. Depression in Parkinson's disease: loss of dopamine and noradrenaline innervation in the limbic system. Brain 2005; 128: 1314-1322.

11 Starkstein SE, Brockman S. Apathy and Parkinson's disease. Curr Treat Options Neurol 2011; 13: 267-273. 
12 Pedersen KF, Alves G, Bronnick K, Aarsland D, Tysnes OB, Larsen JP. Apathy in drug-naive patients with incident Parkinson's disease: the Norwegian ParkWest study. J Neurol 2009; 257: 217-223.

13 Houeto JL, Mesnage V, Mallet L, Pillon B, Gargiulo M, du Moncel ST et al. Behavioural disorders, Parkinson's disease and subthalamic stimulation. J Neurol Neurosurg Psychiatry 2002; 72: 701-707.

14 Castrioto A, Lhommee E, Moro E, Krack P. Mood and behavioural effects of subthalamic stimulation in Parkinson's disease. Lancet Neurol 2014; 13: 287-305.

15 Lewis CJ, Maier F, Eggers C, Pelzer EA, Maarouf M, Moro E et al. Parkinson's disease patients with subthalamic stimulation and carers judge quality of life differently. Parkinsonism Relat Disord 2014; 20: 514-519.

16 Martinez-Fernandez R, Pelissier P, Quesada JL, Klinger H, Lhommee E, Schmitt E et al. Postoperative apathy can neutralise benefits in quality of life after subthalamic stimulation for Parkinson's disease. J Neurol Neurosurg Psychiatry 2015; pii: jnnp-2014-310189.

17 Brissaud E. Vingt-troisième leçon. Nature et pathogénie de la maladie de Parkinson. In: Meige H (ed). Leçons sur les maladies nerveuses: la Salpêtrière, 18931894. Masson: Paris, France, 1895, pp 488-501.

18 Krack P, Pagonabarraga J, Strafella AP, Kulisevsky J. Apathy: who cares? Lancet Neurol 2015; 14: 465.

19 APA. Diagnostic and Statistical Manual of Mental Disorders-DSM IV, 4th edn. American Psychiatric Association: Washington, DC, USA, 1994.

20 APA Diagnostic and Statistical Manual of Mental Disorders-DSM 5, 5th edn American Psychiatric publishing: Washington, DC, USA, 2013.

21 Craufurd D, Thompson JC, Snowden JS. Behavioral changes in Huntington Disease. Neuropsychiatry Neuropsychol Behav Neurol 2001; 14: 219-226.

22 van Duijn E, Kingma EM, van der Mast RC. Psychopathology in verified Huntington's disease gene carriers. J Neuropsychiatry Clin Neurosci 2007; 19: 441-448.

23 Drijgers RL, Dujardin K, Reijnders JS, Defebvre L, Leentjens AF. Validation of diagnostic criteria for apathy in Parkinson's disease. Parkinsonism Relat Disord 2010; 16: 656-660.

24 Del-Monte J, Capdevielle D, Gely-Nargeot MC, Yazbek H, Pupier F, Boulenger JP et al. [Evolution of the concept of apathy: the need for a multifactorial approach in schizophrenia]. Encephale 2013; 39: S57-S63.

25 Brown RG, Pluck G. Negative symptoms: the 'pathology' of motivation and goaldirected behaviour. Trends Neurosci 2000; 23: 412-417.

26 Pluck GC, Brown RG. Apathy in Parkinson's disease. J Neurol Neurosurg Psychiatry 2002; 73: 636-642.

27 Marin RS, Biedrzycki RC, Firinciogullari S. Reliability and validity of the Apathy Evaluation Scale. Psychiatry Res 1991; 38: 143-162.

28 Belin D, Jonkman S, Dickinson A, Robbins TW, Everitt BJ. Parallel and interactive learning processes within the basal ganglia: relevance for the understanding of addiction. Behav Brain Res 2009; 199: 89-102.

29 Yin $\mathrm{HH}$, Knowlton BJ. The role of the basal ganglia in habit formation. Nat Rev Neurosci 2006; 7: 464-476.

30 Levy R, Dubois B. Apathy and the functional anatomy of the prefrontal cortexbasal ganglia circuits. Cereb Cortex 2006; 16: 916-928.

31 Schmidt L, d'Arc BF, Lafargue G, Galanaud D, Czernecki V, Grabli D et al. Disconnecting force from money: effects of basal ganglia damage on incentive motivation. Brain 2008; 131: 1303-1310.

32 Isella V, Melzi P, Grimaldi M, lurlaro S, Piolti R, Ferrarese C et al. Clinical, neuropsychological, and morphometric correlates of apathy in Parkinson's disease. Mov Disord 2002; 17: 366-371.

33 Loas G, Krystkowiak P, Godefroy O. Anhedonia in Parkinson's disease: an overview. J Neuropsychiatry Clin Neurosci 2012; 24: 444-451.

34 Der-Avakian A, Markou A. The neurobiology of anhedonia and other rewardrelated deficits. Trends Neurosci 2012; 35: 68-77.

35 Assogna F, Cravello L, Caltagirone C, Spalletta G. Anhedonia in Parkinson's disease: a systematic review of the literature. Mov Disord 2011; 26: 1825-1834.

36 Dujardin K, Langlois C, Plomhause L, Carette AS, Delliaux M, Duhamel A et al. Apathy in untreated early-stage Parkinson disease: relationship with other nonmotor symptoms. Mov Disord 2014; 29: 1796-1801.

37 Lhommee E, Klinger H, Thobois S, Schmitt E, Ardouin C, Bichon A et al. Subthalamic stimulation in Parkinson's disease: restoring the balance of motivated behaviours. Brain 2012; 135: 1463-1477.

38 Rieu I, Martinez-Martin P, Pereira B, De Chazeron I, Verhagen Metman L, Jahanshahi $\mathrm{M}$ et al. International validation of a behavioral scale in Parkinson's disease without dementia. Mov Disord 2015; 30: 705-713.

39 Rodriguez-Oroz MC, Jahanshahi M, Krack P, Litvan I, Macias R, Bezard E et al. Initial clinical manifestations of Parkinson's disease: features and pathophysiological mechanisms. Lancet Neurol 2009; 8: 1128-1139.

40 Schrag A, Horsfall L, Walters K, Noyce A, Petersen I. Prediagnostic presentations of Parkinson's disease in primary care: a case-control study. Lancet Neurol 2015; 14: $57-64$.
41 Aarsland D, Bronnick K, Alves G, Tysnes OB, Pedersen KF, Ehrt U et al. The spectrum of neuropsychiatric symptoms in patients with early untreated Parkinson's disease. J Neurol Neurosurg Psychiatry 2009; 80: 928-930.

42 Poewe W. Non-motor symptoms in Parkinson's disease. Eur J Neurol 2008; 15 14-20.

43 Braak H, Del Tredici K, Rub U, de Vos RA, Jansen Steur EN, Braak E. Staging of brain pathology related to sporadic Parkinson's disease. Neurobiol Aging 2003; 24: 197-211.

44 Czernecki V, Schupbach M, Yaici S, Levy R, Bardinet E, Yelnik J et al. Apathy following subthalamic stimulation in Parkinson disease: a dopamine responsive symptom. Mov Disord 2008; 23: 964-969.

45 Leentjens AF, Koester J, Fruh B, Shephard DT, Barone P, Houben JJ. The effect of pramipexole on mood and motivational symptoms in Parkinson's disease: a meta-analysis of placebo-controlled studies. Clin Ther 2009; 31: 89-98.

46 Seppi K, Weintraub D, Coelho M, Perez-Lloret S, Fox SH, Katzenschlager R et al. The movement disorder society evidence-based medicine review update: treatments for the non-motor symptoms of Parkinson's disease. Mov Disord 2011; 26: S42-S80.

47 Thobois $\mathrm{S}$, Lhommee $\mathrm{E}$, Klinger $\mathrm{H}$, Ardouin C, Schmitt E, Bichon A et al. Parkinsonian apathy responds to dopaminergic stimulation of D2/D3 receptors with piribedil. Brain 2013; 136: 1568-1577.

48 Barone P, Poewe W, Albrecht S, Debieuvre C, Massey D, Rascol O et al. Pramipexole for the treatment of depressive symptoms in patients with Parkinson's disease: a randomised, double-blind, placebo-controlled trial. Lancet Neurol 2010; 9: 573-580.

49 Chaudhuri KR, Martinez-Martin P, Antonini A, Brown RG, Friedman JH, Onofrj M et al. Rotigotine and specific non-motor symptoms of Parkinson's disease: post hoc analysis of RECOVER. Parkinsonism Relat Disord 2013; 19: 660-665.

50 Volkmann J, Daniels C, Witt K. Neuropsychiatric effects of subthalamic neurostimulation in Parkinson disease. Nat Rev Neurol 2010; 6: 487-498.

51 David R, Koulibaly M, Benoit M, Garcia R, Caci H, Darcourt J et al. Striatal dopamine transporter levels correlate with apathy in neurodegenerative diseases. A SPECT study with partial volume effect correction. Clin Neurol Neurosurg 2008; 110: 19-24.

52 Drapier D, Drapier S, Sauleau P, Haegelen C, Raoul S, Biseul I et al. Does subthalamic nucleus stimulation induce apathy in Parkinson's disease? J Neurol 2006; 253: 1083-1091.

53 Le Jeune F, Drapier D, Bourguignon A, Peron J, Mesbah H, Drapier S et al. Subthalamic nucleus stimulation in Parkinson disease induces apathy: a PET study. Neurology 2009; 73: 1746-1751.

54 Fleury V, Pollak P, Gere J, Tommasi G, Romito L, Comberscure C et al. Inhibition of levodopa-induced antiakinetic effects secondary to pallidothalamic pathway stimulation. Mov Disord 2016 (in press).

55 Carcenac C, Favier M, Vachez Y, Lacombe E, Carnicella S, Savasta M et al. Subthalamic deep brain stimulation differently alters striatal dopaminergic receptor levels in rats. Mov Disord 2015; 30: 1739-1749.

56 Drui G, Carnicella S, Carcenac C, Favier M, Bertrand A, Boulet S et al. Loss of dopaminergic nigrostriatal neurons accounts for the motivational and affective deficits in Parkinson's disease. Mol Psychiatry 2014; 19: 358-367.

57 Lindgren HS, Dunnett SB. Cognitive dysfunction and depression in Parkinson's disease: what can be learned from rodent models? Eur J Neurosci 2012; 35: 1894-1907.

58 Bonito-Oliva A, Masini D, Fisone G. A mouse model of non-motor symptoms in Parkinson's disease: focus on pharmacological interventions targeting affective dysfunctions. Front Behav Neurosci 2014; 8: 290.

59 Bonito-Oliva A, Pignatelli M, Spigolon G, Yoshitake T, Seiler S, Longo F et al Cognitive impairment and dentate gyrus synaptic dysfunction in experimental parkinsonism. Biol Psychiatry 2014; 75: 701-710.

60 Vuckovic MG, Wood RI, Holschneider DP, Abernathy A, Togasaki DM, Smith A et al. Memory, mood, dopamine, and serotonin in the 1-methyl-4-phenyl-1,2,3,6 tetrahydropyridine-lesioned mouse model of basal ganglia injury. Neurobiol Dis 2008; 32: 319-327.

61 Favier M, Duran T, Carcenac C, Drui G, Savasta M, Carnicella S. Pramipexole reverses Parkinson's disease-related motivational deficits in rats. Mov Disord 2014; 29: 912-920.

62 Carnicella S, Drui G, Boulet S, Carcenac C, Favier M, Duran T et al. Implication of dopamine D3 receptor activation in the reversion of Parkinson's disease-related motivational deficits. Transl Psychiatry 2014; 4: e401.

63 Santiago RM, Barbiero J, Gradowski RW, Bochen S, Lima MM, Da Cunha C et al. Induction of depressive-like behavior by intranigral 6-OHDA is directly correlated with deficits in striatal dopamine and hippocampal serotonin. Behav Brain Res 2014; 259: 70-77.

64 Campos FL, Carvalho MM, Cristovao AC, Je G, Baltazar G, Salgado AJ et al. Rodent models of Parkinson's disease: beyond the motor symptomatology. Front Behav Neurosci 2013; 7: 175. 
65 Branchi I, D'Andrea I, Armida M, Cassano T, Pezzola A, Potenza RL et al. Nonmotor symptoms in Parkinson's disease: investigating early-phase onset of behavioral dysfunction in the 6-hydroxydopamine-lesioned rat model. J Neurosci Res 2008; 86: 2050-2061.

66 Tadaiesky MT, Dombrowski PA, Figueiredo CP, Cargnin-Ferreira E, Da Cunha C, Takahashi RN. Emotional, cognitive and neurochemical alterations in a premotor stage model of Parkinson's disease. Neuroscience 2008; 156: 830-840.

67 Berghauzen-Maciejewska K, Kuter K, Kolasiewicz W, Glowacka U, Dziubina A, Ossowska $\mathrm{K}$ et al. Pramipexole but not imipramine or fluoxetine reverses the "depressive-like" behaviour in a rat model of preclinical stages of Parkinson's disease. Behav Brain Res 2014; 271: 343-353.

68 Chen L, Deltheil T, Turle-Lorenzo N, Liberge M, Rosier C, Watabe I et al. SK channel blockade reverses cognitive and motor deficits induced by nigrostriatal dopamine lesions in rats. Int J Neuropsychopharmacol 2014; 17: 1295-1306.

69 Winter C, von Rumohr A, Mundt A, Petrus D, Klein J, Lee T et al. Lesions of dopaminergic neurons in the substantia nigra pars compacta and in the ventral tegmental area enhance depressive-like behavior in rats. Behav Brain Res 2007; 184: $133-141$.

70 Eskow Jaunarajs KL, Angoa-Perez M, Kuhn DM, Bishop C. Potential mechanisms underlying anxiety and depression in Parkinson's disease: consequences of L-DOPA treatment. Neurosci Biobehav Rev 2010; 35: 556-564.

71 Carvalho MM, Campos FL, Coimbra B, Pego JM, Rodrigues C, Lima R et al. Behavioral characterization of the 6-hydroxidopamine model of Parkinson's disease and pharmacological rescuing of non-motor deficits. Mol Neurodegener 2013; 8: 14 .

72 Delaville C, Chetrit J, Abdallah K, Morin S, Cardoit L, De Deurwaerdere P et al. Emerging dysfunctions consequent to combined monoaminergic depletions in Parkinsonism. Neurobiol Dis 2012; 45: 763-773.

73 Zhang X, Egeland M, Svenningsson P. Antidepressant-like properties of sarizotan in experimental Parkinsonism. Psychopharmacology (Berl) 2011; 218: 621-634.

74 Hui YP, Wang T, Han LN, Li LB, Sun YN, Liu J et al. Anxiolytic effects of prelimbic 5-HT(1 A) receptor activation in the hemiparkinsonian rat. Behav Brain Res 2015; 277: $211-220$

75 Eskow Jaunarajs KL, George JA, Bishop C. L-DOPA-induced dysregulation of extrastriatal dopamine and serotonin and affective symptoms in a bilateral rat model of Parkinson's disease. Neuroscience 2012; 218: 243-256.

76 Dardou D, Chassain C, Durif F. Chronic pramipexole treatment increases tolerance for sucrose in normal and ventral tegmental lesioned rats. Front Neurosci 2015; 8: 437.

77 Eskow Jaunarajs KL, Dupre KB, Ostock CY, Button T, Deak T, Bishop C. Behavioral and neurochemical effects of chronic L-DOPA treatment on nonmotor sequelae in the hemiparkinsonian rat. Behav Pharmacol 2010; 21: 627-637.

78 Balleine BW, O'Doherty JP. Human and rodent homologies in action control: corticostriatal determinants of goal-directed and habitual action. Neuropsychopharmacology 2010; 35: 48-69.

79 Darbaky Y, Forni C, Amalric M, Baunez C. High frequency stimulation of the subthalamic nucleus has beneficial antiparkinsonian effects on motor functions in rats, but less efficiency in a choice reaction time task. Eur J Neurosci 2003; 18: 951-956.

80 Baunez C, Robbins TW. Effects of dopamine depletion of the dorsal striatum and further interaction with subthalamic nucleus lesions in an attentional task in the rat. Neuroscience 1999; 92: 1343-1356.

81 Pioli EY, Meissner W, Sohr R, Gross CE, Bezard E, Bioulac BH. Differential behavioral effects of partial bilateral lesions of ventral tegmental area or substantia nigra pars compacta in rats. Neuroscience 2008; 153: 1213-1224.

82 Baunez C, Amalric M, Robbins TW. Enhanced food-related motivation after bilateral lesions of the subthalamic nucleus. J Neurosci 2002; 22: 562-568.

83 Kish SJ, Shannak K, Hornykiewicz O. Uneven pattern of dopamine loss in the striatum of patients with idiopathic Parkinson's disease. Pathophysiologic and clinical implications. N Engl J Med 1988; 318: 876-880.

84 Javoy-Agid F, Agid Y. Is the mesocortical dopaminergic system involved in Parkinson disease? Neurology 1980; 30: 1326-1330.

85 Berridge KC. The debate over dopamine's role in reward: the case for incentive salience. Psychopharmacology (Berl) 2007; 191: 391-431.

86 Bromberg-Martin ES, Matsumoto M, Hikosaka O. Dopamine in motivational control: rewarding, aversive, and alerting. Neuron 2010; 68: 815-834.

87 Koob GF, Stinus L, Le Moal M. Hyperactivity and hypoactivity produced by lesions to the mesolimbic dopamine system. Behav Brain Res 1981; 3: 341-359.

88 Le Moal M, Simon H. Mesocorticolimbic dopaminergic network: functional and regulatory roles. Physiol Rev 1991; 71: 155-234.

89 Nieoullon A, Coquerel A. Dopamine: a key regulator to adapt action, emotion, motivation and cognition. Curr Opin Neurol 2003; 16: S3-S9.

90 Castagne V, Moser P, Roux S, Porsolt RD. Rodent models of depression: forced swim and tail suspension behavioral despair tests in rats and mice. Curr Protoc Neurosci 2011; Chapter 8: Unit 8.10A.
91 Nestler EJ, Carlezon WA Jr. The mesolimbic dopamine reward circuit in depression. Biol Psychiatry 2006; 59: 1151-1159.

92 Tye KM, Mirzabekov JJ, Warden MR, Ferenczi EA, Tsai HC, Finkelstein J et al. Dopamine neurons modulate neural encoding and expression of depressionrelated behaviour. Nature 2013; 493: 537-541.

93 Matheus FC, Rial D, Real J, Lemos C, Takahashi RN, Bertoglio LJ et al. Temporal dissociation of striatum and prefrontal cortex uncouples anhedonia and defense behaviors relevant to depression in 6-OHDA-lesioned rats. Mol Neurobiol advance online publication, 12 July 2015; e-pub ahead of print.

94 Olds J. Drives and Reinforcements: Behavioral Studies of Hypothalamic Functions. Raven Press: New York, NY, USA, 1977.

95 Salamone JD, Correa M, Farrar A, Mingote SM. Effort-related functions of nucleus accumbens dopamine and associated forebrain circuits. Psychopharmacology (Berl) 2007; 191: 461-482.

96 Sun T, He W, Hu G, Li M. Anxiolytic-like property of risperidone and olanzapine as examined in multiple measures of fear in rats. Pharmacol Biochem Behav 2010; 95: 298-307.

97 Dauer W, Przedborski S. Parkinson's disease: mechanisms and models. Neuron 2003; 39: 889-909.

98 Wise RA. Roles for nigrostriatal-not just mesocorticolimbic-dopamine in reward and addiction. Trends Neurosci 2009; 32: 517-524.

99 Beninger RJ, Ranaldi R. Microinjections of flupenthixol into the caudate-putamen but not the nucleus accumbens, amygdala or frontal cortex of rats produce intra-session declines in food-rewarded operant responding. Behav Brain Res 1993; 55: 203-212.

100 Fibiger HC, Zis AP, McGeer EG. Feeding and drinking deficits after 6hydroxydopamine administration in the rat: similarities to the lateral hypothalamic syndrome. Brain Res 1973; 55: 135-148.

101 Ungerstedt U. Adipsia and aphagia after 6-hydroxydopamine induced degeneration of the nigro-striatal dopamine system. Acta Physiol Scand Suppl 1971; 367: 95-122.

102 Zis AP, Fibiger HC, Phillips AG. Reversal by L-dopa of impaired learning due to destruction of the dopaminergic nigro-neostriatal projection. Science 1974; 185 : 960-962.

103 Hollerman JR, Schultz W. Dopamine neurons report an error in the temporal prediction of reward during learning. Nat Neurosci 1998; 1: 304-309.

104 Hollerman JR, Tremblay L, Schultz W. Influence of reward expectation on behavior-related neuronal activity in primate striatum. J Neurophysiol 1998; 80: 947-963.

105 Ilango A, Kesner AJ, Keller KL, Stuber GD, Bonci A, Ikemoto S. Similar roles of substantia nigra and ventral tegmental dopamine neurons in reward and aversion. J Neurosci 2014; 34: 817-822.

106 Rossi MA, Sukharnikova T, Hayrapetyan VY, Yang L, Yin HH. Operant self-stimulation of dopamine neurons in the substantia nigra. PLoS One 2013; 8: e65799.

107 Joyce JN. Dopamine D3 receptor as a therapeutic target for antipsychotic and antiparkinsonian drugs. Pharmacol Ther 2001; 90: 231-259.

108 Sokoloff P, Diaz J, Le Foll B, Guillin O, Leriche L, Bezard E et al. The dopamine D3 receptor: a therapeutic target for the treatment of neuropsychiatric disorders. CNS Neurol Disord Drug Targets 2006; 5: 25-43.

109 Bezard E, Ferry S, Mach U, Stark H, Leriche L, Boraud T et al. Attenuation of levodopa-induced dyskinesia by normalizing dopamine D3 receptor function. Nat Med 2003; 9: 762-767.

110 Bordet R, Ridray S, Carboni S, Diaz J, Sokoloff P, Schwartz JC. Induction of dopamine D3 receptor expression as a mechanism of behavioral sensitization to levodopa. Proc Natl Acad Sci USA 1997; 94: 3363-3367.

111 Jeanblanc J, He DY, McGough NN, Logrip ML, Phamluong K, Janak PH et al. The dopamine D3 receptor is part of a homeostatic pathway regulating ethanol consumption. J Neurosci 2006; 26: 1457-1464.

112 Simpson EH, Winiger V, Biezonski DK, Haq I, Kandel ER, Kellendonk C. Selective overexpression of dopamine D3 receptors in the striatum disrupts motivation but not cognition. Biol Psychiatry 2014; 76: 823-831.

113 Bjorklund A, Dunnett SB. Dopamine neuron systems in the brain: an update. Trends Neurosci 2007; 30: 194-202.

114 Guillin O, Diaz J, Carroll P, Griffon N, Schwartz JC, Sokoloff P. BDNF controls dopamine D3 receptor expression and triggers behavioural sensitization. Nature 2001; 411: 86-89.

115 Cenci MA, Francardo V, O'Sullivan SS, Lindgren HS. Rodent models of impulsive compulsive behaviors in Parkinson's disease: how far have we reached? Neurobiol Dis 2015; 82: 561-573.

116 Seeman P. Parkinson's disease treatment may cause impulse-control disorder via dopamine D3 receptors. Synapse 2015; 69: 183-189.

117 Visanji NP, Gomez-Ramirez J, Johnston TH, Pires D, Voon V, Brotchie JM et al. Pharmacological characterization of psychosis-like behavior in the MPTPlesioned nonhuman primate model of Parkinson's disease. Mov Disord 2006; 21: 1879-1891. 
118 Brown CA, Campbell MC, Karimi M, Tabbal SD, Loftin SK, Tian LL et al. Dopamine pathway loss in nucleus accumbens and ventral tegmental area predicts apathetic behavior in MPTP-lesioned monkeys. Exp Neurol 2012; 236: 190-197.

119 Tian L, Xia Y, Flores HP, Campbell MC, Moerlein SM, Perlmutter JS. Neuroimaging analysis of the dopamine basis for apathetic behaviors in an MPTP-lesioned primate model. PLoS One 2015; 10: e0132064.

120 Durand E, Petit O, Tremblay L, Zimmer C, Sgambato-Faure V, Chassain C et al. Social behavioral changes in MPTP-treated monkey model of Parkinson's disease. Front Behav Neurosci 2015; 9: 42.

121 Faggiani E, Delaville C, Benazzouz A. The combined depletion of monoamines alters the effectiveness of subthalamic deep brain stimulation. Neurobiol Dis 2015; 82: 342-348.

122 Lee M, Ryu YH, Cho WG, Kang YW, Lee SJ, Jeon TJ et al. Relationship between dopamine deficit and the expression of depressive behavior resulted from alteration of serotonin system. Synapse 2015; 69: 453-460.

123 Politis M, Niccolini F. Serotonin in Parkinson's disease. Behav Brain Res 2015; 277 136-145.

124 Haber SN, Knutson B. The reward circuit: linking primate anatomy and human imaging. Neuropsychopharmacology 2010; 35: 4-26.

125 Ikemoto S. Dopamine reward circuitry: two projection systems from the ventral midbrain to the nucleus accumbens-olfactory tubercle complex. Brain Res Rev 2007; 56: 27-78.

126 Ferreira JG, Del-Fava F, Hasue RH, Shammah-Lagnado SJ. Organization of ventral tegmental area projections to the ventral tegmental area-nigral complex in the rat. Neuroscience 2008; 153: 196-213.

127 Belin D, Everitt BJ. Cocaine seeking habits depend upon dopamine-dependent serial connectivity linking the ventral with the dorsal striatum. Neuron 2008; 57 432-441.

128 Murray JE, Belin-Rauscent A, Simon M, Giuliano C, Benoit-Marand M, Everitt BJ et al. Basolateral and central amygdala differentially recruit and maintain dorsolateral striatum-dependent cocaine-seeking habits. Nat Commun 2015; 6: 10088.

129 Yelnik J. Modeling the organization of the basal ganglia. Rev Neurol (Paris) 2008; 164: $969-976$

130 Joel D, Niv Y, Ruppin E. Actor-critic models of the basal ganglia: new anatomical and computational perspectives. Neural Netw 2002; 15: 535-547.

131 O'Doherty J, Dayan P, Schultz J, Deichmann R, Friston K, Dolan RJ. Dissociable roles of ventral and dorsal striatum in instrumental conditioning. Science 2004; 304: $452-454$
132 Funkiewiez A, Ardouin C, Krack P, Fraix V, Van Blercom N, Xie J et al. Acute psychotropic effects of bilateral subthalamic nucleus stimulation and levodopa in Parkinson's disease. Mov Disord 2003; 18: 524-530.

133 Krack P, Kumar R, Ardouin C, Dowsey PL, McVicker JM, Benabid AL et al. Mirthful laughter induced by subthalamic nucleus stimulation. Mov Disord 2001; 16: 867-875.

134 Mallet L, Schupbach M, N'Diaye K, Remy P, Bardinet E, Czernecki V et al. Stimulation of subterritories of the subthalamic nucleus reveals its role in the integration of the emotional and motor aspects of behavior. Proc Natl Acad Sci USA 2007; 104: 10661-10666.

135 Welter ML, Schupbach M, Czernecki V, Karachi C, Fernandez-Vidal S, Golmard JL et al. Optimal target localization for subthalamic stimulation in patients with Parkinson disease. Neurology 2014; 82: 1352-1361.

136 Tan SK, Hartung H, Schievink S, Sharp T, Temel Y. High-frequency stimulation of the substantia nigra induces serotonin-dependent depression-like behavior in animal models. Biol Psychiatry 2013; 73: e1-e3.

137 Gradinaru V, Mogri M, Thompson KR, Henderson JM, Deisseroth K. Optical deconstruction of parkinsonian neural circuitry. Science 2009; 324: 354-359.

138 Caudal D, Alvarsson A, Bjorklund A, Svenningsson P. Depressive-like phenotype induced by AAV-mediated overexpression of human alpha-synuclein in midbrain dopaminergic neurons. Exp Neurol 2015; 273: 243-252.

139 Petit GH, Berkovich E, Hickery M, Kallunki P, Fog K, Fitzer-Attas C et al. Rasagiline ameliorates olfactory deficits in an alpha-synuclein mouse model of Parkinson's disease. PLoS One 2013; 8: e60691.

140 McDowell K, Chesselet MF. Animal models of the non-motor features of Parkinson's disease. Neurobiol Dis 2012; 46: 597-606.

141 Furlanetti LL, Coenen VA, Aranda IA, Dobrossy MD. Chronic deep brain stimulation of the medial forebrain bundle reverses depressive-like behavior in a hemiparkinsonian rodent model. Exp Brain Res 2015; 233: 3073-3085.

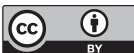

This work is licensed under a Creative Commons Attribution 4.0 international License. The images or other third party material in this article are included in the article's Creative Commons license, unless indicated otherwise in the credit line; if the material is not included under the Creative Commons license, users will need to obtain permission from the license holder to reproduce the material. To view a copy of this license, visit http://creativecommons.org/licenses/ by/4.0/ 